\title{
All about information - balancing ICT, IRS, users and making a difference
}

\author{
Ina Fourie \\ Department of Information Science, University of Pretoria, Pretoria, South Africa
}

\begin{abstract}
Purpose - The purpose of this contribution is to set the scenario for pursuing options to find a balance between information communication technology (ICT), information retrieval systems (IRS) such as databases, library catalogues, repositories, Google Scholar, digital libraries, portals, search engines and the users of these systems. Whose needs are served: the real users' with contemporary needs or the perceived users and their research tasks whom we intensely studied in the early years of databases and computerised information services?
\end{abstract}

Design/methodology/approach - The contribution will be written against the background of research from information retrieval and information behaviour.

Findings - Although developments in ICT open a wealth of opportunities to study and serve the needs of a wide spectrum of information users, IRS are often on the surface level still very traditional in the needs they service: analytical information seeking according to planned search strategies, browsing, monitoring trends and changes through alerting services and RSS, and encouragement and support for authors to publish. Some are offering a bit more, but little aimed at the under-graduate soon to enter professional workplace.

Originality/value - Although there are many publications on databases and other IRS and their users, and numerous one's on information behaviour I am not aware of other reports on the latest services aimed at specific user groups, and which focus on the need to consider the totality of their work and everyday life worlds.

Keywords - Information Communication Technology, information retrieval systems, information services, students, users

Paper type - Research

Introduction

Ever since the introduction of computers and information retrieval systems (IRS), researchers and practitioners have focused on information and ensuring timely and precise access to accurate and relevant information. Early day researchers argued about relevance, pertinence and utility (Harter 1986; Soergel 1985). Laws of Library Science - affecting library services - were formulated by Ranganathan, and further expanded by others to include the increasing variety of media that can be used to reach and serve users (Simpson 2008). Codes for ethical conduct and the requirements for a profession were argued. Who should search online databases was frequently asked in the early days of IRS? Which skills and qualities were required? What worked best: natural language or controlled vocabulary? Which search strategies worked best: the building block approach, successive pair search strategies or citation pearl growing? (Harter, 1986). Mercia Bates (1989) argued the importance of "berry picking techniques" in the design of information retrieval systems (IRS). Taylor (1968) noted the difficulties in expressing information needs. Information Retrieval 
and Information Organisation was established and refined as fields of research aimed at improving access to information.

Bourne and Hahn (2003) captured developments in the online industry up to 1967. It is amazing to note the retrieval power at the time in terms of search features: proximity searching, limitation according to fields, and the use of online thesauri - all aimed at improving recall, precision and novelty (i.e. finding only new information on a topic) of search results. Many issues concerning the improvement of search results were thus addressed.

With the advent of CD-ROMs the focus moved to the end-user and arguments that training is certainly no longer needed (Martin \& Nicholas 1993). Databases became more intuitive to use; with CD-ROMs no extra costs were at stake for time spent on searching. People could do their own searches. It was argued that librarians and information specialists were no longer essential; they feared disintermediation (Fourie, 1999).

The IRSs were, however, not quite as intuitive and user-friendly as thought. Information literacy and even workplace information literacy soon became topics of discussion and urgent issues to address (Dodd 2007; Streatfield, Allen \& Wilson, 2010). With the advent of the Internet even more people had access to information. Users were no longer only researchers, scientists, doctors and academics - they included students, children and people from all walks of life (Case, 2012). The Internet, search engines such as Google, and social networking tools such as Facebook, Twitter and bookmarking tools such as Delicious became part of everyday life information behaviour. The right of access to information, bridging the digital divide, and fighting Internet censorship, are at the order of the day. Access to information became ubiquitous with wireless access, mobiles and tablets. IRSs are argued to be smarter, more intuitive and more supportive. Advice on the design of IRSs seems to lean towards mimicking Google and Google Scholar and supporting the needs of the Net or Google generation (Gibbons 2007; Thelwall 2005). Access to information must be quick and seamless with little regard of whether the information comes from the Web or an expensive subscription database. Facilities supporting multitasking seem non-negotiable. But how to support the users of subscription information services such as databases, aggregator services and journal platforms to consider information as a key component in their daily life where work and/or study takes the largest portion of time and where more than one role (work as-well as everyday life) are often at stake? Perhaps the key question in competing with Google is to ask who these users are and what they require from a one-stop departure for quality information supporting their jobs and tasks, and positioning themselves in a demanding work environment and society.

The intention of this contribution is to take academic contexts (universities, colleges and other institutions of higher or tertiary education) as point of departure and to see how information service providers cater for the information needs of different target groups. In fact, which target groups are catered for, and how are developments in information communication technology (ICT) employed?

\section{In search of the magic intersection}

In supporting the information behaviour of people such as the users in an academic context, it is not only about the ICT or IRS. Neither is it just about the users. The crux lies in finding a balance between ICT, IRS and the users in a specific context as depicted in Figure 1. But where to start - the technological support available through the IRS, the content of the IRS, or the users and their preferences and practices? Does it matter where we start, or does the crux lies in how we pull it together? This contribution will focus on the users targeted by IRS to which academic libraries and information services typically subscribes and their use of ICT at present - thus subscription information services. 


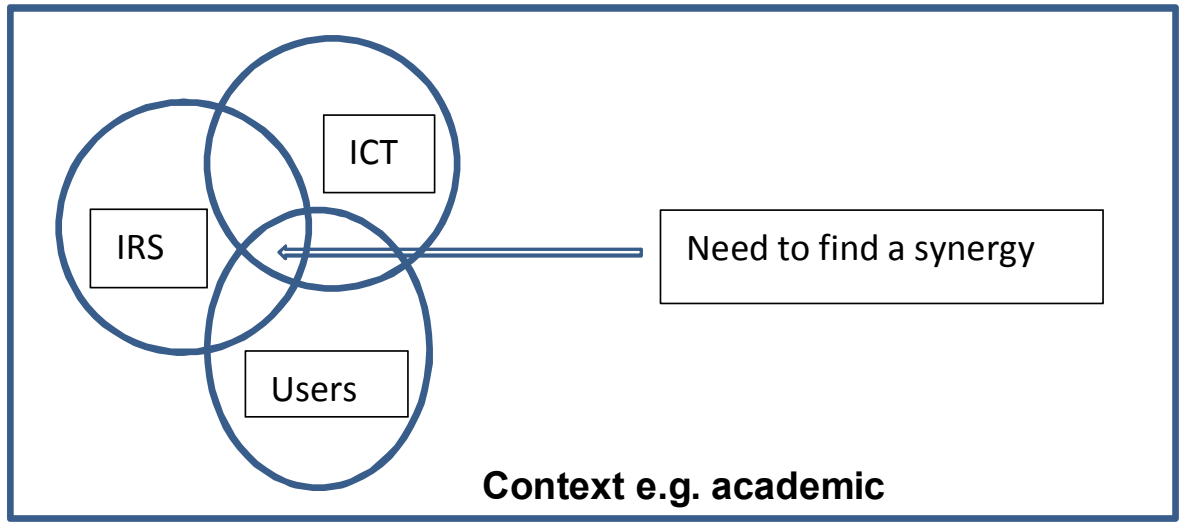

Figure 1: Finding a synergy between IRS, ICT and user groups in context

\section{Literature review}

Many information retrieval systems are available. In academic contexts there are for example the library catalogue, databases and journal platforms, Google Scholar, repositories and digital libraries. Considerable research has been reported on how these services are used (Case 2012) using various terms related to information behaviour: information seeking, information gathering, information sharing, and library use. (I am highlighting these terms since they, if studied in their own right, might give important pointers for positioning IRS in academic contexts). Asunka et al. (2009) studied academic information seeking habits through the log analysis of a teachers' college library website, Dee and Stanley (2005) report on the information seeking of nursing students and clinical nurses, Dodd (2007) on veterinary students, Du and Evans (2011) on information seeking related to research tasks and search strategies, He et al. (2012) on undergraduate students' interaction with online information resources in their academic tasks, and Mizrachi (2010) on under-graduate students behaviour in the library. Research findings focus on the preference for Google and Google Scholar, lack of interest in databases, concerns about information literacy skills, and especially poor skills in evaluating the quality of information. However, do they prefer Google due to the familiarity of the interface, or because it offers a seamless and easy manner to obtain information? Does a competitive edge to Google lies in offering a one stop point of departure to full-filling a spectrum of information needs? Are these needs subject related (i.e. finding information on research questions including assignments), or are there more to the needs of users to address?

Booker, Detlor, and Serenko (2012) report on the factors affecting the adoption of online library resources by business students. They found that "... it is the independent, continuous use of OLR [online library resouces] after receiving initial, formal ILI [information literacy instruction] that creates continued positive effects. Importantly, OLR self-efficacy and anxiety were found to be important antecedents to OLR adoption. OLR anxiety also partially mediates the relationship between self-efficacy and perceived ease of use". Studies also include attempts to organise the library to suit the habits of students' behaviour in gathering information (Chai 2007), and the work of Fulton, Kerins and Madden (2004) on the information seeking of students studying towards a professional career. As pointed out by Given (2002) academic life is not only about studies; for many students, especially more mature students, studies are inter-mingled with everyday life responsibilities and information needs. Powell and Partridge (2010) also refer to life in the "real world". For students as well as faculty, it is not only about finding journal articles, but also about books (Rowlands \& Nicholas 2008). In fact, it is about the total spectrum of digital information and services that 
might be of relevance to students (Nicholas et al. 2009; Rowley \& Urquhart 2007; Urquhart \& Rowley 2007).

In academic contexts there are many issues at stake that can be addressed by subscription information services intending to be the one stop points of departure for users: (1) institutions need to be competitive in research and educational contexts on a national as well as international level - they need to establish niche areas of excellence; (2) faculty need to position themselves in terms of teaching, research, community service and collaboration; (3) post-graduate students need to master not only the status quo of research findings on their research topics, but also the appropriate research frameworks, paradigms, theories and research methodologies, getting published, promoting their research findings and establishing collaborative links to either theory or practice; (4) in mastering subject content under-graduate students need to be introduced to the ethics and challenges of professional workplace, and building a career.

The question arises: who are the providers of subscription information services targeting, and how are they targeting users from academic contexts? Would it be meaningful for them to become the one stop point of departure for their users - the academic home to work from? Not all issues can be addressed in this contribution; the first issue to determine is what is currently on offer.

\section{Who are targeted by subscription information services?}

By their very nature and content it is assumed that the information services to which academic libraries and information services subscribe are aimed at researchers - including faculty and their students doing research for post-graduate studies. Qualified professionals and institutions who can afford subscription also find these useful as is clear from information behaviour studies in professional contexts such as for engineers, doctors, and lawyers (Case, 2012). Under-graduate students are expected to use subscription information services after receiving some information literacy training. To what extent are these groups, however targeted in the services and support offered, and what is required to gain and keep their interest?

There are many information services to which libraries and information services in academic services subscribe. The most popular are Emerald, ScienceDirect, EbscoHost, Proquest, ISI Web of Science and Ingenta Connect. In the following paragraphs a few other providers of subscription information services are considered; it is not intended as a comprehensive survey, but merely as a pointer to the status quo, and to stimulate thoughts on finding a synergy between IRS, ICT developments and the users. What should subscription information service providers consider in ensuring that their services becomes one stop services for users in academic contexts - even after moving into workplace.

Some information service providers clearly highlight target groups on their home page; for others you need to delve a bit to find services specifically aimed at faculty and students, or professional societies - sometimes starting with a link to services aimed at librarians. For some such as the ACM Digital Library, the target group is implied e.g. as experts, with no differentiation in services and support aimed at specific groups. For SpringerLink the target group is not explicitly indicated, although some services are clearly aimed at librarians such as information statistics, technical detail on the administration dashboards, and policy on interlibrary lending.

The American Chemical Society (ACS) as information service provider is very clear in their targeted users: library users in general, librarians, authors and reviewers, and members of the society. It has a very interesting array of services such as the free ACS ChemWorx, and options to synchronise pdf's from lab groups and manuscripts. The American Institute of 
Physics (AIP) highlight their support services for librarians, authors and advertisers.

Although offering very useful content for students and educators, this is not explicitly stated on the home page; a link for Physics Resources and then Physics Education, brings the user to GradSchoolShopper, offering information on a variety of issues including podcasts of interest to academics and students.

Wiley Online Library is aimed at researchers, librarians, societies, authors, open access, advertisers, cooperate partners, media and agents. For researchers they offer citation tracking, reference managers, early view of publications, content alerts, saved alerts, RSS feeds, and options to recommend publications to the library. For librarians there is a side bar with articles of interest for library and information professionals. These include articles from Journal of the American Society for Information Science and Technology and Health and Information Libraries Journals (these are titles published by Wiley). There are also links to weblogs and interviews; product information; policies e.g. on accessibility, developing world access, and long term preservation; as well as various sources for librarians such as on customer administration, pricing and licensing, and library newsletters.

Taylor and Francis Online targets librarians, authors and editors, and societies. For librarians they offer link resolvers, usage reports, training and promotional material, pricing, licensing and philanthropic information. They have a special service (Special Terms for Authors \& Researchers (STAR)) to increase access to scholarly content for individual academic and scientific authors from economically constrained parts of the world during the authoring process. They also offer AuthorAID, an innovative author support and mentoring program coordinated by INASP. The program assists researchers in emerging countries to communicate their work more effectively. The goal is to increase the success rate of researchers in obtaining publication and, ultimately, to increase the visibility and influence of research undertaken in emerging regions. In addition Taylor and Francis offers author guides on preparing an article, choosing a journal, open access, etc. To enable authors to add the latest information, they offer 7 days of complementary access to their content.

Under the option for "Information and Services", SAGE offers links for authors, librarians, individual users, and societies and their members. For librarians they have information on account services, access and usage information, subscription information, information on various aspects of searching journals, and advise on how to drive usage of the services. For individual users they have tools to receive email alerts for new articles or issues, options to save selected citations, customise searches, and mark favourite journals, subscription to RSS feeds, and links to various social bookmarking services. Various information and sources typically expected for authors are in place e.g. guidelines for publishing and submitting publications. Following the link for librarians and usage driving material, SAGE offers information related to courses such as academic and student research, business, councelling, education, health, social work, and women studies and subjects such as study skills, clinical medicine, and communication and media studies. For faculty there is access to review and examination copies, and for individual users there are options for email alerts, RSS feeds, and the use of social bookmarks. Due to its focus as publisher, SAGE also offers excellent information and support on research methods.

RSC Publishing is another service provider offering interesting additional services such as blogs (Analyst blogs, Analytical methods blog and the Biomaterials Science blog). Their ChemistryWorlds service includes podcasts, jobs, opinions, and even a video with tips on publishing. There is information on Education in Chemistry with an RSS feed for education in Chemistry, and Education in Chemistry on Twitter, Facebook and Linkedln. There is also TalkChemistry and Chemspider (http://www.chemspider.com/), a free chemical database. Services offered to professional societies (mostly those publishing with the information service provider) can offer an important link to the world of workplace. These include resources for societies and exchange blogs. Wiley also offer guidelines on nurturing new 
volunteers, building a society board, support services in managing membership, strengthening digital capabilities, publication ethics, and advise on peer review. SAGE also targets societies. Services to authors (books and journal articles) are provided by publishers such as Wiley, Taylor and Francis and Emerald and include ethical issues, English language editing, reference styles, and sometimes also links to books on writing research papers. From an information seeking point, the services to be expected are mostly available such as browsing publications according to subject category or type of publication (e.g. books, journal articles). ACM Digital Library also allows for browsing according to special interest groups, conferences, and special collections. Apart from access to journal articles and books, many also explicitly include conference papers and proceedings, patents and magazines. Although offering interfaces to target groups with various levels of sophistication (novice, advanced, command language), there seems to be no differentiation in terms of academic readiness (e.g. under-graduate, post-graduate and expert researchers).

Although a spectrum of additional services are offered these do not cover the full spectrum of users, and certainly very little that is specifically aimed at the under-graduate student, who is to be convinced that a service can offer an academic home and more ease and comfort than Google.

\section{Conclusion}

This contribution touched on the need for information service providers (especially the subscription services subscribed to in academic contexts) to find a synergy between IRS, ICT developments and their users. A first step is to note what is on offer by subscription information services. It is for each information service provider to take a critical look at (1) their target groups and how these are indicated on their websites; (2) the services they offer for these groups - and again how these are indicated, and brought to the attention of the target groups; (3) what they can learn from the services noted here and by making an indepth study of what is on offer by other information service providers; and then (4) to consider options to go ahead and plan additional information services that can position them as academic homes and one-stop points of departure for users. The challenge lies in catering explicitly for under-graduate students - the information users of the future. What do they need to form a bridge between their academic studies and the workplace of the future and everyday life? How can their needs, as well as the needs of other users be studied in more depth? These are issues to be addressed in future.

\section{References}

Asunka, S. et al. (2009), "Understanding academic information seeking habits through analysis of web server log files: the case of the teachers college library website", Journal of Academic Librarianship Vol. 35 No. 1, pp. 33-45.

Bates, M.J. (1989), "The design of browsing and berrypicking techniques for the online search interface", Online Information Review Vol. 13 No. 5, pp. 407-424

Booker, L.D., Detlor, B. \& Serenko, A. (2012), "Factors affecting the adoption of online library resources by business students", Journal of the American Society for Information Science and Technology Vol. 63 No. 12, pp. 2503-2520.

Bourne, C.P. \& Hahn, T.B. (2003), A History of Online Information Services, 1963-1976, MIT Press, Cambridge, MA. 
Chai, I. (2007), "Organizing the library to suit the undergraduates' information gathering behavior at the Tel-Hai Academic College in Israel", Joumal of Academic Librarianship Vol. 33 No. 4, pp. 485-491.

Dee, C. \& Stanley, E.E. (2005), "Information-seeking behavior of nursing students and clinical nurses: implications for health sciences librarians", Journal of the Medical Library Association Vol. 93 No. 2, pp. 213-222.

Dodd, L. (2007), "The impact of problem-based learning on the information behavior and literacy of veterinary medicine students at University College Dublin", Journal of Academic Librarianship Vol. 33 No. 2, pp. 206-216.

Du, J.T. \& Evans, N. (2011), "Academic users' information searching on research topics: characteristics of research tasks and search strategies", Journal of Academic Librarianship Vol. 37, pp. 299-306.

Fulton, C., Kerins, G. \& Madden, R. (2004), "Information seeking and students studying for professional careers: the cases of engineering and law students in Ireland" Information Research Vol. 10 No. 1 Online. http://informationr.net/ir/10-1/paper208.html Accessed: 31 May 2013.

Gibbons, S. (2007), The Academic Library and the Net Gen Student: Making the Connections, American Library Association, Chicago, IL.

Given, L.M. (2002), "The academic and the everyday: investigating the overlap in mature undergraduates' information-seeking behaviors", Library and Information Science Research Vol. 24 No. 1, pp. 17-29.

Harter, S.P. (1986), Online information retrieval: concepts, principles and techniques, Academic Press, Orlando.

He, D. et al. (2012), "Undergraduate students' interaction with online information resources in their academic tasks: A comparative study", Aslib Proceedings: New Information Perspectives Vol. 64, No. 6, pp. 615-640.

Martin, H. \& Nicholas, D. (1993), End-users coming of age? Six years of end-user searching at The Guardian. Online and CD-ROM Review, Vol. 17, No. 2, pp. 83-90.

Mizrachi, D. (2010), “Undergraduates' academic information and library behaviors: preliminary results”, Reference Services Review Vol. 38 No. 4, pp. 571-580.

Nicholas, D. et al. (2009), "Student digital information-seeking behaviour in context", Journal of Documentation Vol. 65 No. 1, pp.106-132.

Powell, T. \& Partridge, H. (2010), "Life in the "real world": a profile of Queensland University of Technology library and information science graduates", Australian Academic \& Research Libraries Vol. 41 No. 2, pp. 113-128.

Rowlands, I. \& Nicholas, D. (2008),"Understanding information behaviour: how do students and faculty find books?", Journal of Academic Librarianship, Vol. 34 No. 1, pp. 3-15.

Rowley, J. \& Urquhart, C. (2007), "Understanding student information behavior in relation to electronic information services: Lessons from longitudinal monitoring and evaluation, part 1", Journal of the American Society for Information Science and Technology, Vol. 58 No. 8, pp. 1162-1174. 
Simpson, C. 2008. "Five Laws", Library Media Connection, Vol. 26 No. 7/6, p. 6. Available online http://www.carolsimpson.com/5laws.pdf; Accessed: 2 June 2013.

Soergel, D. (1985), Organizing information: principles of data base and retrieval systems, Academic Press, San Diego.

Streatfield, D., Allen, D. \& Wilson, T. (2010), "Information literacy training for postgraduate and postdoctoral researchers: a national survey and its implications" Libri, Vol. 60 No. 3, pp. 230-240.

Taylor, R.S. (1968), "Question-negotiation and information seeking in libraries", College and Research Libraries, Vol. 29, No. ${ }^{* *}$, pp. 178-89.

Thelwall, M. (2005), "Directing students to new information types: a new role for Google in literature searches?”, Internet Reference Services Quarterly, Vol. 10 No. 3/4, pp. 159-166.

Urquhart, C. \& Rowley, J. (2007), "Understanding student information behavior in relation to electronic information services: lessons from longitudinal monitoring and evaluation, Part 2", Journal of the American Society for Information Science and Technology Vol. 58 No. 8, pp. 1188-1197.

Corresponding author

Ina Fourie can be contacted at: ina.fourie@up.ac.za 